\title{
Optimization of methane output for an anaerobic waste digester
}

\author{
A. A. Khan ${ }^{1}$ A. J. Stacey ${ }^{2} \quad$ J. J. Shepherd ${ }^{3}$
}

(Received 5 November 2012; revised 31 July 2013)

\begin{abstract}
In response to the need for renewable energy resources, the replacement of fuel gas with methane produced from the anaerobic digestion of sewerage, agricultural and municipal solid wastes is considered. The utilization of methane for power generation offsets the energy requirements of the digester facility. We discuss the optimization of methane output for a model digester. The model uses Monod based kinetics of methane fermentation and does not include spatial effects. The model assumes that the solid waste acts as a substrate for acid forming bacteria which produce volatile fatty acids, which is converted to methane by a second type of bacteria. It is found that the initial concentrations of the two bacteria and biodegradable volatile solids that maximize the total methane output are independent of the temperature. However, the optimal hydraulic residence time and initial concentration of
\end{abstract}

http://journal.austms.org.au/ojs/index.php/ANZIAMJ/article/view/6322 gives this article, (C) Austral. Mathematical Soc. 2013. Published September 3, 2013, as part of the Proceedings of the 16th Biennial Computational Techniques and Applications Conference. ISSN 1446-8735. (Print two pages per sheet of paper.) Copies of this article must not be made otherwise available on the internet; instead link directly to this URL for this article. 
volatile fatty acids are temperature dependent. This suggests that flow rates should be adjusted, depending on the temperature, to maximize methane output.

Keywords: optimization, application, anerobic, methane

\section{Contents}

1 Introduction

2 Governing equations

3 Results

4 Conclusion

C535

References

C538

\section{Introduction}

Anaerobic digestion of sewerage sludge, agricultural and municipal solid wastes produces a digester gas (biogas) principally composed of methane and carbon dioxide. The utilization of the methane gas for power generation partially offsets the energy requirements of the digester facility. Since this methane replaces fossil fuels, it contributes to the sustainability of our energy supply. Since this fuel resource is also increasing with population, it is important to optimize its production in order to maximize the possible power generated. However, the burning of methane produces carbon dioxide and the consequent carbon tax must be taken into account when assessing the economic viability of such a scheme. This study will not consider these economic aspects.

A two step model (acidogenesis-methanogensis) is considered. In the first step the organic substrates are first disintegrated and hydrolysed, then transformed 
into volatile fatty acids by acidogenic bacteria. In the second step, the methanogenic bacteria consume the volatile fatty acids and convert them to methane and carbon dioxide.

We consider the Monod based model of Hill [1] which describes the fermentation kinetics. The model consists of four first order coupled nonlinear differential equations. Two equations describe the rate of change of concentration of the two substrates, the biodegradable volatile solids $S_{\mathrm{Bvs}}$, and the volatile fatty acids $S_{\mathrm{VFA}}$. The two other differential equations describe the rate of change of concentration of the acid producing bacteria $X_{a}$ and the methane producing bacteria $X_{m}$.

As discussed by Husain [5], Hill's model provides a balance between complexity and accuracy. Hill's model was shown to give a reasonable fit to data for different manures and methane production rates. More sophisticated models exist, such as the ADM1 model proposed by Batstone et al. [6]. However, these models have over 29 dynamic state variables that are difficult to fit to the data.

We consider a semi-batch process [7] where the digester has an initial volume into which two substrates are continuously fed and sludge is continuously removed in such a way as to maintain a constant volume. Because the methanogenic bacteria concentration decreases over time, even with a steady in flow of substrates the composition of the contents of the digester vary over time. The methanogenic bacteria will eventually die out, resulting in a finite practical batch period.

Two times are key in this process: the hydraulic residence time and the processing time. The hydraulic residence time is feed volumetric rate divided by the reactor liquid volume. The processing time starts from zero and goes to 20 days. Since we are interested in optimizing the total volume of methane produced (per volume of substrate) and the process is semi-batch we need to choose a fixed time over which to optimize. A time of 20 days is chosen as this is considered to be the longest practical period for a batch [1]. 


\section{Governing equations}

The four concentrations $S_{\mathrm{BVS}}, S_{\mathrm{VFA}}, X_{\mathrm{a}}$ and $X_{m}$ with initial values $S_{\mathrm{BVS} 0}, S_{\mathrm{VFA} 0}$, $X_{a 0}$ and $X_{m 0}$, respectively, are governed by

$$
\begin{aligned}
\frac{d S_{\mathrm{BVS}}}{d t} & =\frac{S_{\mathrm{BVSO}}-S_{\mathrm{BVS}}}{\theta}-\frac{\mu_{\mathrm{a}} X_{\mathrm{a}}}{Y_{\mathrm{a}}}, \\
\frac{\mathrm{d} S_{\mathrm{VFA}}}{\mathrm{dt}} & =\frac{S_{\mathrm{VFA} 0}-S_{\mathrm{VFA}}}{\theta}-\frac{\mu_{m} X_{m}}{Y_{m}}+\frac{\mu_{a} X_{a}\left(1-Y_{a}\right)}{Y_{a}}, \\
\frac{d X_{a}}{d t} & =\left(\mu_{a}-k_{a}-\frac{1}{\theta}\right) X_{a}, \\
\frac{d X_{m}}{d t} & =\left(\mu_{m}-k_{m}-\frac{1}{\theta}\right) X_{m},
\end{aligned}
$$

where $\theta$ is the hydraulic residence time, $\mu_{a}$ and $\mu_{m}$ are the growth rates of the two bacteria and other parameters are defined in Table 1. The first two equations govern the concentration of the biodegradable volatile solids and volatile fatty acids, respectively, whereas the second two govern the concentrations of the acid producing bacteria and methane producing bacteria, respectively. The growth rates for the two bacteria, $\mu_{a}$ and $\mu_{m}$, are both functions of the two concentrations $S_{\mathrm{BVS}}$ and $S_{\mathrm{VFA}}$, and hence are functions of time. The system of equations for the four concentrations, $S_{\mathrm{BVS}}, S_{\mathrm{VFA}}$, $X_{a}$ and $X_{m}$, was solved numerically using the Runge-Kutta algorithm ode45 in Matlab [9].

The specific growth rates are

$$
\begin{aligned}
\mu_{a} & =\frac{\mu_{\mathrm{amax}}}{1+k_{\mathrm{BVS}} / S_{\mathrm{BVS}}+S_{\mathrm{VFA}} / k_{\mathrm{ia}}}, \\
\mu_{\mathrm{m}} & =\frac{\mu_{\mathrm{mmax}}}{1+k_{\mathrm{VFA}} / S_{\mathrm{VFA}}+S_{\mathrm{VFA}} / k_{\mathrm{im}}} .
\end{aligned}
$$

Following Andrews [8], $\mu_{\mathrm{amax}}$ and $\mu_{\operatorname{mmax}}$ are the maximum specific growth rates in the absence of inhibition for the acidogenic and methanogenic reactions, respectively. 
Table 1: Nomenclature. Parameter values are all taken from Hill [1]. Symbols Definitions

\begin{tabular}{l}
\hline$t$ \\
$\mu_{\mathrm{amax}}, \mu_{\operatorname{mmax}}$ \\
$S_{\mathrm{BVSO}}$ \\
$S_{\mathrm{BVS}}$ \\
$\theta$ \\
$S_{\mathrm{VFAO}}$ \\
$S_{\mathrm{VFA}}$ \\
$X_{\mathrm{a} 0}$ \\
$X_{\mathrm{a}}$ \\
$X_{\mathrm{mo}}$ \\
$X_{\mathrm{m}}$ \\
$\gamma_{\mathrm{CH}}$ \\
$Y_{\mathrm{a}}=0.1$ \\
$Y_{\mathrm{m}}=0.005$ \\
$\mathrm{k}_{\mathrm{a}}=0.1 \mu_{\mathrm{amax}}$ \\
$\mathrm{k}_{\mathrm{m}}=0.1 \mu_{\mathrm{mmax}}$ \\
$\mathrm{k}_{\mathrm{BVs}}=9$ \\
$\mathrm{k}_{\mathrm{vFA}}=2$ \\
$\mathrm{k}_{\mathrm{ia}}=12$ \\
$\mathrm{k}_{\mathrm{im}}=6$
\end{tabular}

time, days

maximum specific growth of acid and methane formers respective, $1 /$ day

concentration of influent biodegradable volatile solids (BVS), g/L

concentration of BVS in the digester, $\mathrm{g} / \mathrm{L}$

hydraulic residence time, days

concentration of influent volatile fatty acids (VFA), g/L

concentration of VFA in the digester, $\mathrm{g} / \mathrm{L}$

concentration of initial acidogenic bacteria in the liquid digester, $\mathrm{g} / \mathrm{L}$

concentration of acidogenic bacteria in the digester, $\mathrm{g} / \mathrm{L}$ concentration of initial acidogenic bacteria in the liquid digester, $\mathrm{g} / \mathrm{L}$

concentration of methanogenic bacteria in the digester, $\mathrm{g} / \mathrm{L}$

volumetric methane productivity rate, L/day

yield coefficient of acidogenic bacteria, dimensionless

yield coefficient of methanogenic bacteria, dimensionless

specific death rate of acidogenic bacteria, 1/day

specific death rate of methanogenic bacteria, 1/day

Monod half-velocity for BVS, 1/day

Monod half-velocity for VFA, 1/day

inhibition coefficient for acidogenic bacteria, 1/day inhibition coefficient for methanogenic bacteria, 1/day 
At time $t=0$, when the batch process begins, the bacteria increases via growth and decreases via both death and dilution, that is, by being washed out in the constant outflow. The constant inflow concentrations of the two substrates are chosen to be equivalent to the initial substrate concentrations $S_{\mathrm{BVSO}}$ and $S_{\mathrm{VFA}}$, respectively. Here, only biologically active solids are considered.

For the biodegradable volatile solids, governed by equation (1), the first term on the right hand side is the rate of change in concentration caused by dilution. The second term is the rate of change in concentration caused by the conversion of the biodegradable volatile solids into volatile fatty acids (by the acid producing bacteria), where $Y_{a}$ is a yield coefficient for the acid producing bacteria with $0<Y_{a}<1$. For volatile fatty acids, governed by equation (2), the first term on the right hand side is the rate of change caused by dilution, whereas the second term is the rate of change in concentration caused by the conversion of the volatile fatty acids into methane and carbon dioxide. The last term is the rate of change due to the conversion of biodegradable volatile solids into volatile fatty acids and assumes the biodegradable volatile solids must be converted into volatile fatty acids before other products are produced by the acidogenic and methanogenic bacteria. Other products are involved in the chain of reactions but only those involved in the production of methane are included in the model. In equations (3) and (4) the specific growth rates $\mu_{a}$ and $\mu_{m}$ are reduced by the temperature dependent death rates $k_{a}$ and $k_{m}$, respectively, as well as dilution effects. Both the specific growth rates are assumed to be subject to inhibition. The condition for the acid bacteria to grow is $\mu_{a}>k_{a}+1 / \theta$, and for the methane bacteria to grow, $\mu_{m}>k_{m}+1 / \theta$. In the calculations that follow we use the simplifying assumptions $k_{a}=0.1 \mu_{a \max }$ and $k_{m}=0.1 \mu_{\operatorname{mmax}}[1,2]$.

As with all kinetic studies, the reaction rates vary with temperature. In this model the reaction kinetic component is determined by the two kinetic parameters $\mu_{a \max }$ and $\mu_{\operatorname{mmax}}$. We adopt the simplifying assumption that $\mu_{\text {amax }}$ and $\mu_{\max }$ are equal and set to $\mu_{\max }$ [1]. Measurements of their variation with temperature were given by Chen and Hashimoto [4] and shown 


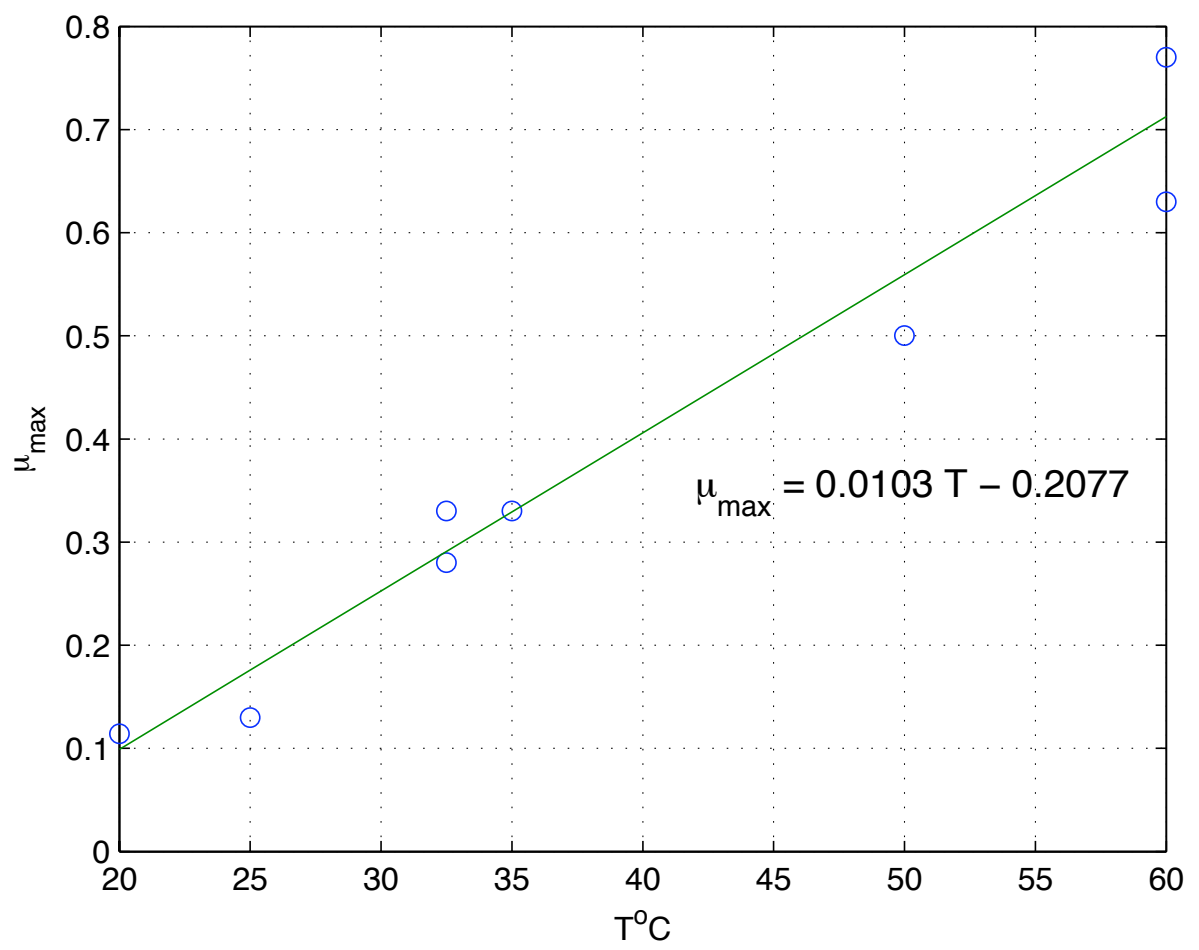

Figure 1: Variation of $\mu_{\max }(1 /$ day $)$ with temperature.

in Figure 1. These measurements are based on various substrates including sewage sludge, municipal refuse, dairy waste and beef waste.

The volumetric rate of methane generated (measured at standard temperature and pressure) was found by Hill [2] to be proportional to the bacteria concentration $X_{m}$ and the growth rate $\mu_{m}$ of the methanogenic bacteria,

$$
\gamma_{\mathrm{CH}_{4}}=0.5 \mu_{\mathrm{m}} X_{\mathrm{m}} \frac{\left(1-\mathrm{Y}_{\mathrm{m}}\right)}{\mathrm{Y}_{\mathrm{m}}} \text {. }
$$

We are interested the total volume of methane, per liquid volume of the 
Table 2: Inputs for fmincon

\begin{tabular}{lccc} 
Parameters & Initial guess & Lower bound & Upper bound \\
\hline $\mathrm{S}_{\text {BVSO }}(\mathrm{g} / \mathrm{L})$ & 36.0 & 1 & 60 \\
$\mathrm{~S}_{\mathrm{VFAO}}(\mathrm{g} / \mathrm{L})$ & 2.52 & 0.00005 & 60 \\
$\theta$ (days) & 7 & 5 & 30 \\
$\mathrm{X}_{\mathrm{a} 0}(\mathrm{~g} / \mathrm{L})$ & 0.48 & 0.00001 & 1 \\
$\mathrm{X}_{\mathrm{m} 0}(\mathrm{~g} / \mathrm{L})$ & 0.30 & 0.00001 & 1
\end{tabular}

reactor, generated over the 20 day period,

$$
\mathrm{V}_{\mathrm{CH}_{4}}=\int_{0}^{20} \gamma_{\mathrm{CH}_{4}} \mathrm{dt} \text {. }
$$

We optimize this total volume with respect to five key parameters, the four initial concentrations $S_{\mathrm{BVSO}}, S_{\mathrm{VFAO}}, \mathrm{X}_{\mathrm{a} 0}$ and $\mathrm{X}_{\mathrm{a} 0}$, and the hydraulic residence time $\theta$.

\section{Results}

For the results to be of practical value we need to restrict the ranges of the four initial concentrations and the hydraulic residence time to values that are meaningful. For example, the temperature range should not exceed the temperature at which the bacteria can operate. The ranges were taken from typical values reported by Hill [3]. We used the active-set algorithm in fmincon, a Matlab implementation of constrained optimization implementing the Karush-Kuhn-Tucker algorithm, efficient for medium size problems. In this algorithm the constrained problem is transformed to a basic unconstrained problem by using penalty functions for constraints that are near or beyond the constraint boundary. The algorithm also requires an initial guess of the solution, as well as upper and lower bounds. These values are displayed in Table 2. 
Table 3: Optimization outputs for five $\mu_{\max }$ (1/day) values with concentrations $S_{\mathrm{BVSO}}, S_{\mathrm{VFAO}}, X_{\mathrm{a} 0}$ and $X_{\mathrm{mo}}(\mathrm{g} / \mathrm{L})$, time $\theta$ (days) and volume $\mathrm{V}_{\mathrm{CH}_{4}}(\mathrm{~L})$.

\begin{tabular}{rrrrrrr}
$\mu_{\max }$ & $S_{\mathrm{BVSO}}$ & $S_{\mathrm{VFAO}}$ & $X_{\mathrm{a} 0}$ & $X_{\mathrm{m} 0}$ & $\theta$ & $\mathrm{V}_{\mathrm{CH}_{4}}$ \\
\hline 0.10 & 60 & 29 & 1.0 & 1.0 & 12 & 34 \\
0.20 & 60 & 39 & 1.0 & 1.0 & 22 & 58 \\
0.30 & 60 & 41 & 1.0 & 1.0 & 11 & 89 \\
0.40 & 60 & 43 & 1.0 & 1.0 & 7.5 & 121 \\
0.50 & 60 & 43 & 1.0 & 1.0 & 5.6 & 152
\end{tabular}

The optimization was run for five different $\mu_{\max }$ values, which, as shown in Figure 1, correspond to five different temperatures. The results are displayed in Table 3.

It was found that the volume of methane increased with an increase in $\mu_{\max }$, as expected. The initial concentrations $S_{\mathrm{Bvs}}, X_{\mathrm{a} 0}$ and $X_{\mathrm{mo}}$ maximized the methane output in the 20 day period when they themselves were maximized, and this was not affected by the temperature. In contrast, the initial concentration $S_{\mathrm{VFA} O}$ and the hydraulic residence time $\theta$ varied with temperature. Therefore, in order to reach the maximum output of total methane, a high concentration of influent biodegradable volatile solids and both kinds of bacteria are needed. The input parameter that varied the most with temperature was $\theta$, the hydraulic residence time. This decreased significantly with higher $\mu_{\max }$ (that is, higher temperatures). Therefore, at lower temperatures we need longer hydraulic residence times to maximize the production of methane.

To further explore the behavior of the system at different temperatures we use the optimum parameters from the results above to examine the variation with time of the four state variables $S_{\mathrm{BVS}}, S_{\mathrm{VFA}}, X_{\mathrm{a}}$ and $X_{m}$. This is done for kinetic parameters $\mu_{\max }=0.1,0.2,0.3$ and 0.5 which correspond to temperatures in the range of $22^{\circ} \mathrm{C}$ to $47^{\circ} \mathrm{C}$.

The variation with time of the four state variables is shown in Figures 2-5. The variation of the methane volume growth rate $\gamma_{\mathrm{CH} 4}$ and parameter $\mu_{m}$ 


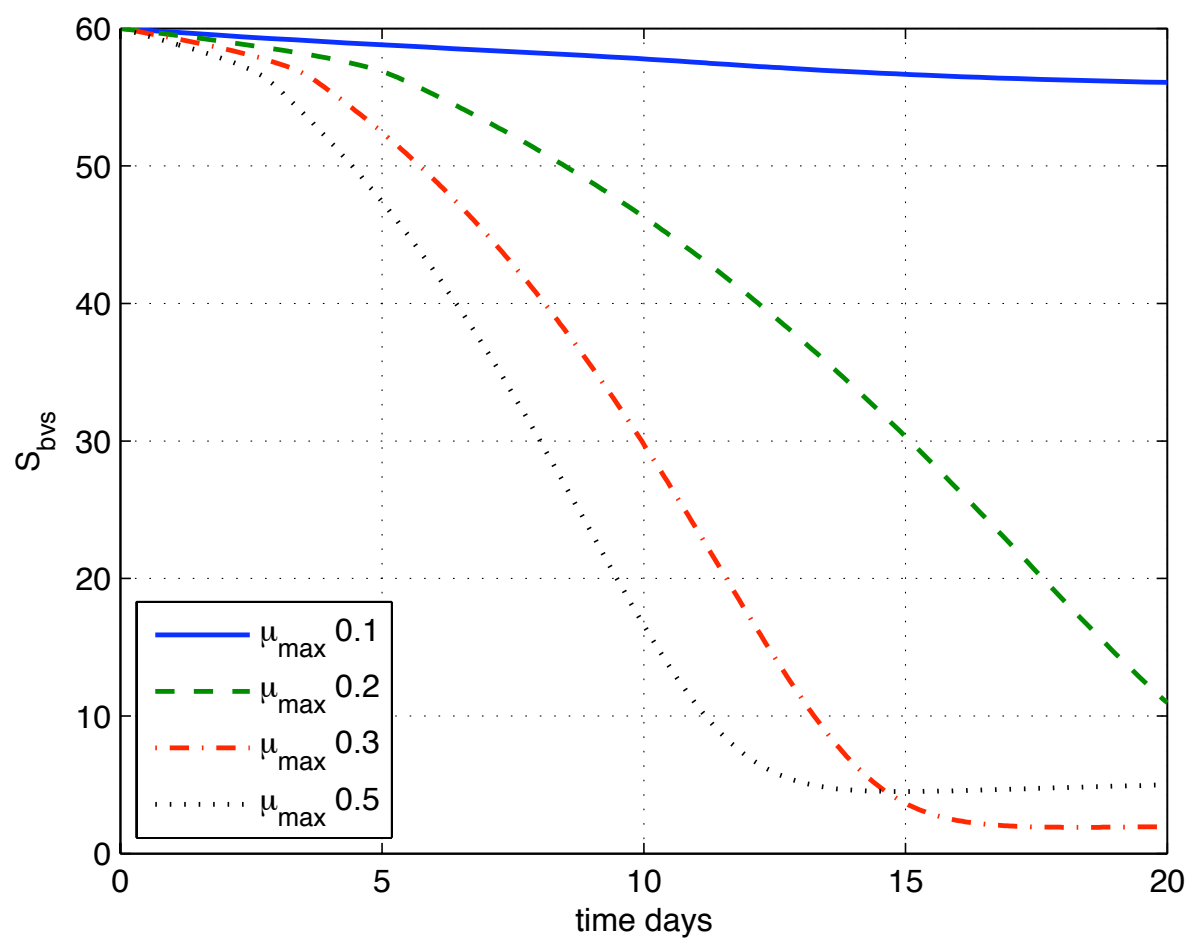

Figure 2: Variation of $S_{\mathrm{BvS}}(\mathrm{g} / \mathrm{L})$ with time, for $\mu_{\max }=0.1,0.2,0.3,0.51 /$ day.

with time are shown in Figures 6 and 7 . The volume growth rate of methane generated, shown in Figures 6 , is generally higher for higher values of $\mu_{\max }$, and reaches its peak output sooner for larger $\mu_{\max }$.

The variation in the concentration of the methanogenic bacteria with time, Figure 5 , decreases as $\mu_{\max }$, or the temperature, increases, with the exception of $\mu_{\max }=0.1$. The reason for the decrease is the quick increase in acidogenic bacteria, shown in Figure 4. This results in higher concentrations of volatile fatty acids which inhibit the the growth of methanogenic bacteria. The exception is the low temperature case with $\mu_{\max }=0.1$ at which the acidogenic 


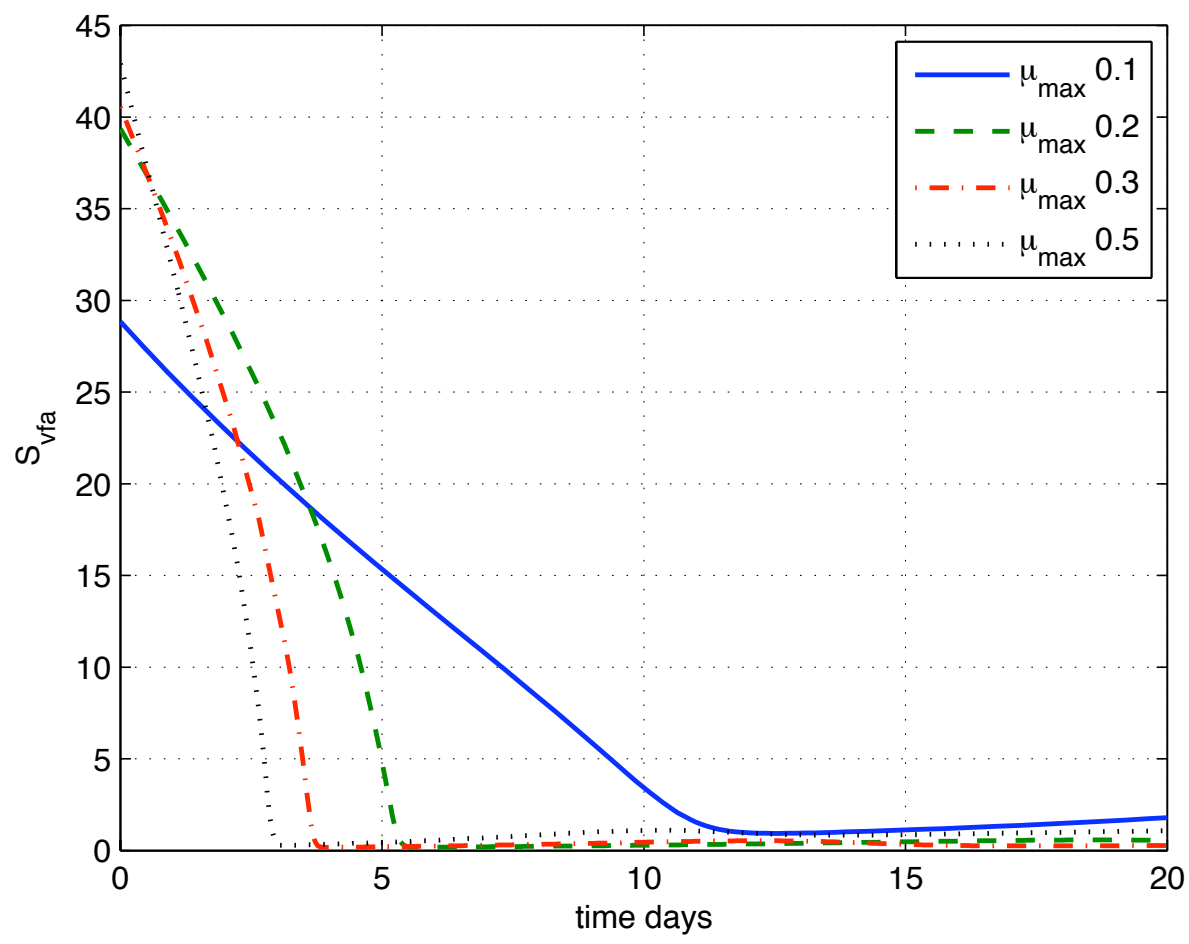

Figure 3: Variation of $S_{\mathrm{VFA}}(\mathrm{g} / \mathrm{L})$ with time, for $\mu_{\max }=0.1,0.2,0.3,0.51 /$ day.

bacteria do not grow. The volume rate of methane generated is accounted for by the corresponding large increases in $\mu_{m}$ with $\mu_{\max }$, shown in Figure 7 . The decrease in the volatile fatty acid concentrations, seen in Figure 3, is due to its conversion to methane and carbon dioxide, which proceeds more rapidly than the conversion of biodegradable volatile solids to volatile fatty acids. These concentrations only increase when the rate of conversion of biodegradable volatile solids to volatile fatty acids increases. This conversion process is initially limited by the level of acidogenic bacteria. As the acidogenic bacteria concentrations increase, Figure 4, there is a corresponding increase 


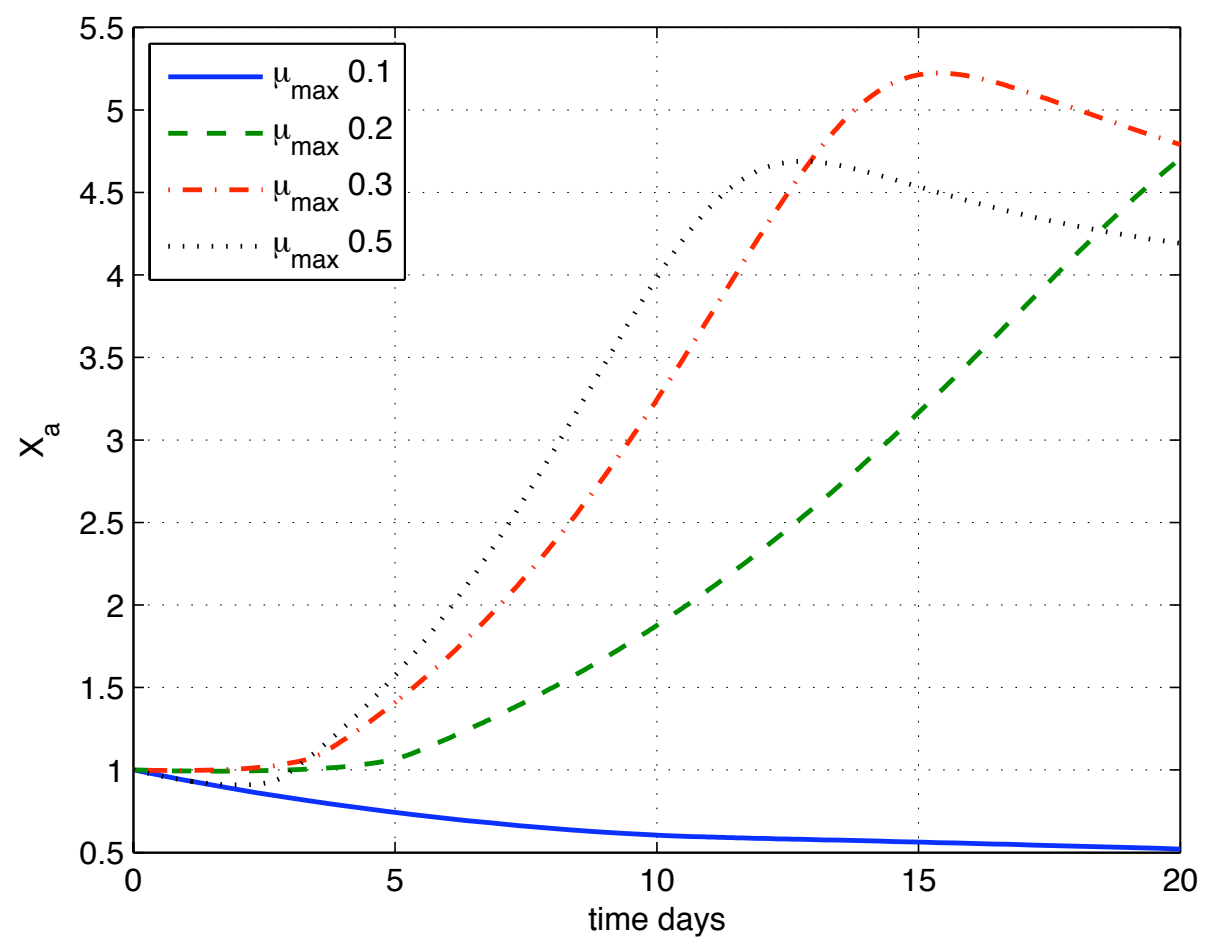

Figure 4: Variation of $X_{a}(\mathrm{~g} / \mathrm{L})$ with time, for $\mu_{\max }=0.1,0.2,0.3,0.51 /$ day.

in the volatile fatty acids, Figure 3, and decrease in biodegradable volatile solids, Figure 2. The exception is when $\mu_{\max }=0.1$ where the population of acidogenic bacteria decreases.

The methanogenic bacteria concentration is shown in Figure 5 and generally decreases with time. This decrease is caused by the combined rates of death and washing out of the bacteria exceeding the growth rate. 


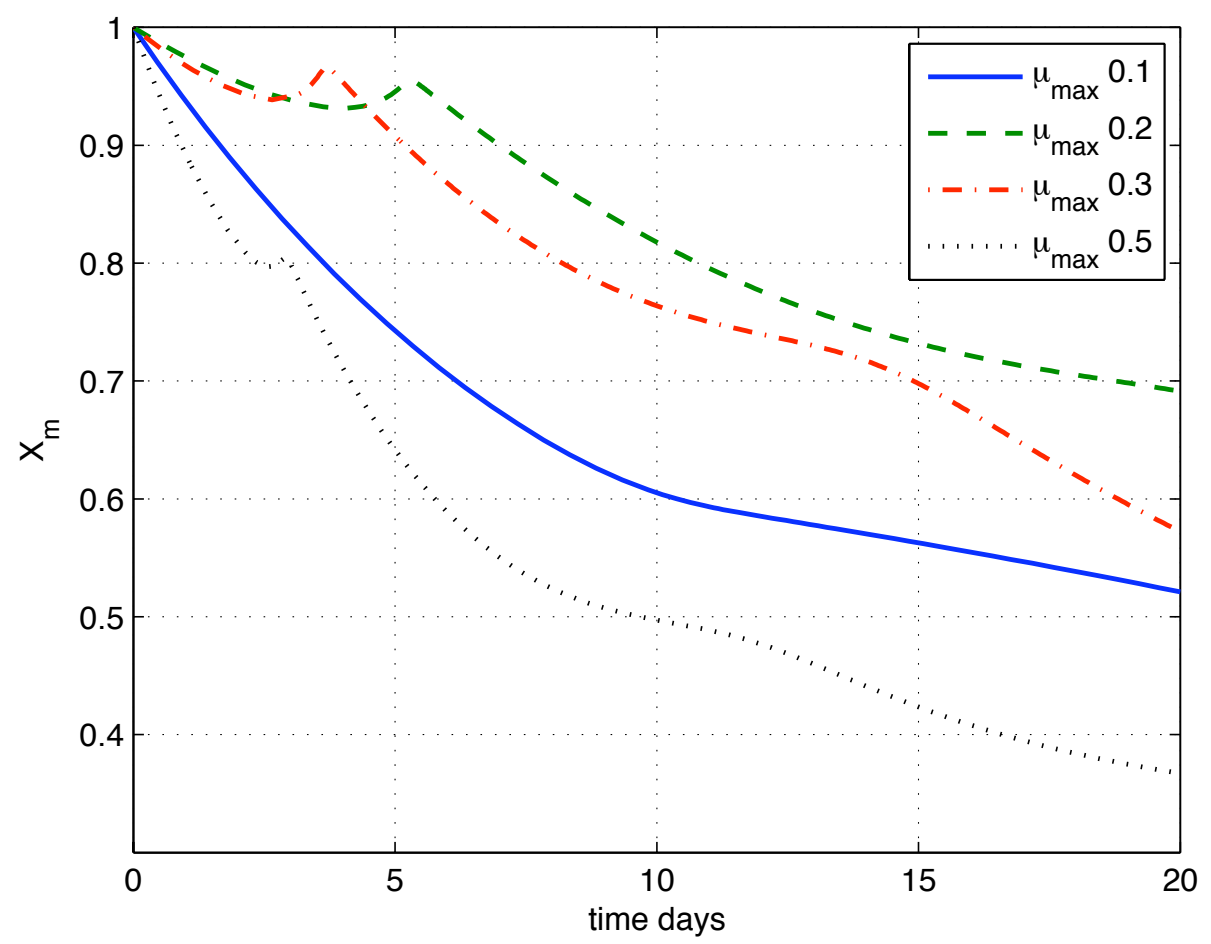

Figure 5: Variation of $X_{m}(\mathrm{~g} / \mathrm{L})$ with time, for $\mu_{\max }=0.1,0.2,0.3,0.51 /$ day.

\section{Conclusion}

This article looks at the factors that impact methane production for a simple semi-batch digester model. The key parameters controlling the process are the initial concentrations of the two substrates, $S_{\mathrm{BVsO}}$ and $S_{\mathrm{VFA} O}$, the initial concentrations of the two bacteria, $X_{a 0}$ and $X_{a 0}$, the hydraulic residence time, $\theta$, and the kinetic parameter $\mu_{\max }$, which is essentially the temperature. It was found that, for initial concentrations restricted to allowable values, 


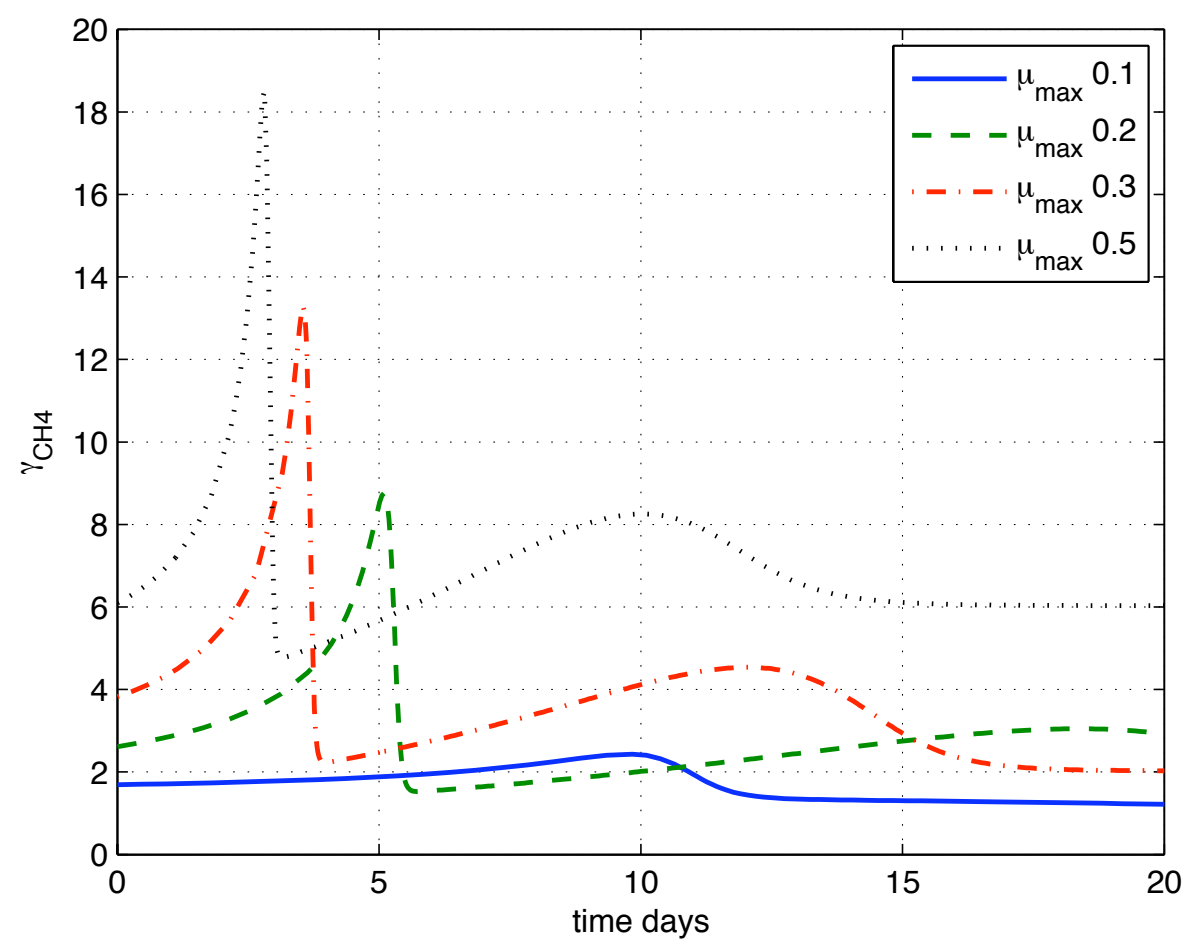

Figure 6: Variation of $\gamma_{\mathrm{CH}_{4}}$ (L/day), the volumetric rate of methane production, with time, for $\mu_{\max }=0.1,0.2,0.3,0.51$ day.

the methane production was maximized when the initial concentrations of the two bacteria and the biodegradable volatile solids were maximized. This was independent of temperature. In contrast, the initial concentration of the volatile fatty acid and the hydraulic residence time which maximised the volume of methane both depended on temperature. The variation of the hydraulic residence time $\theta$ with temperature should be shorter for higher temperatures and longer for lower temperatures. This leads to a number of interesting possibilities. The hydraulic residence time, defined as total liquid 


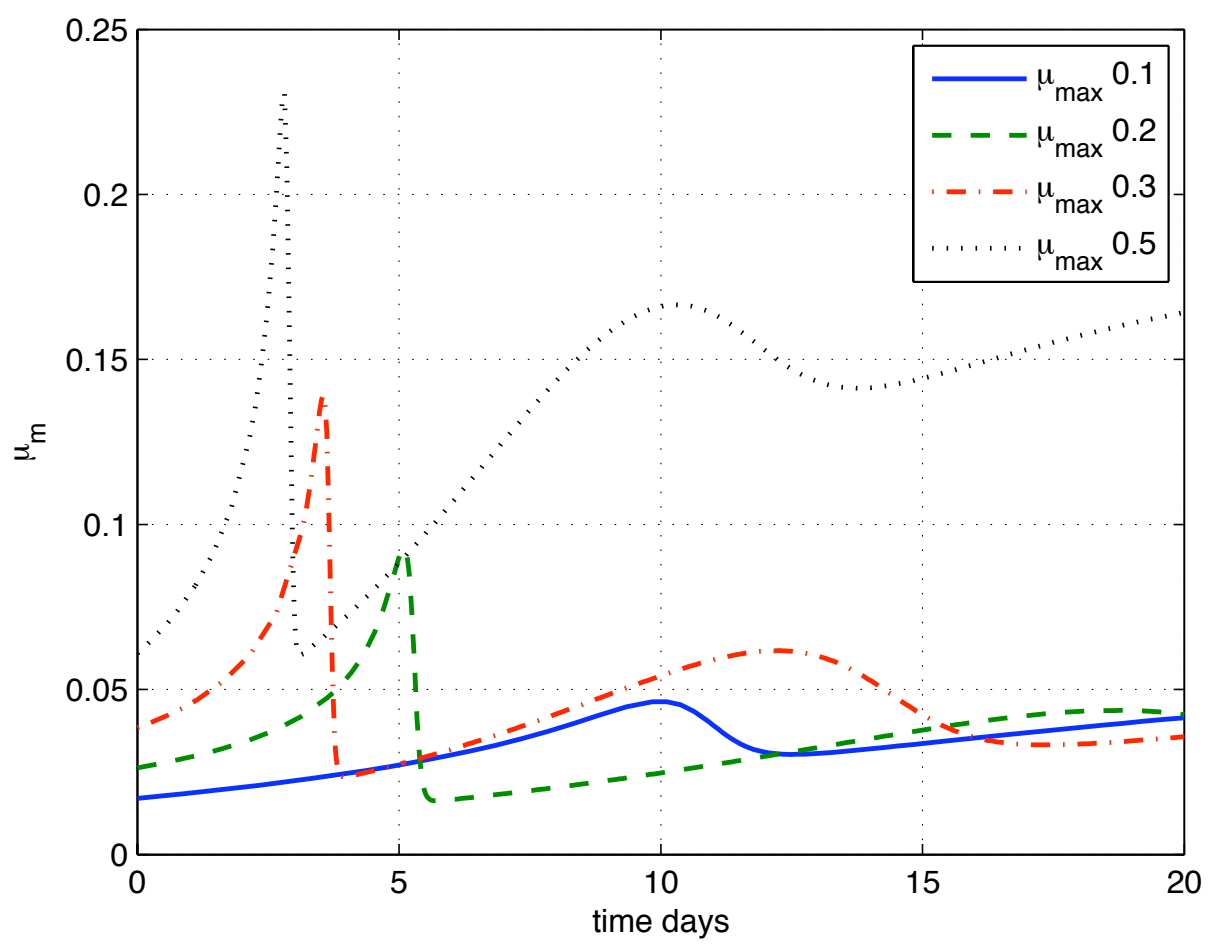

Figure 7: Variation of $\mu_{\mathrm{m}}(1 /$ day $)$, the methane specific growth rate, with time, for $\mu_{\max }=0.1,0.2,0.3,0.51 /$ day.

volume/volumetric feed flow, is adjusted in one of two ways: changing the volumetric feed flow or changing the total liquid volume of the digester. The first of these is relatively simple to implement and suggests the possibility of adjusting the flow rate between winter and summer months, for example. The second possibility is achievable by reducing the volume. 


\section{References}

[1] D. T. Hill, Simplified Monod Kinetics of Methane Fermentation of Animal Wastes, Agricultural Wastes, 5:1-16 (1983). doi:10.1016/0141-4607(83)90009-4 C525, C527, C528

[2] D. T. Hill, E. W. Tollner and R. D. Holmberg, The Kinetics of Inhibition in Methane Fermentation of Swine Manure, Agricultural Wastes, 5:105-123 (1983). doi:10.1016/0141-4607(83)90089-6 C528, C529

[3] D. T. Hill, Design Parameters and Operating Characteristics of Animal Waste Anaerobic Digestion Systems - Swine and Poultry, Agricultural Wastes, 5:157-178 (1983). doi:10.1016/0141-4607(83)90081-1 C530

[4] Y. R. Chen and A. G. Hashimoto, The Kinetics of Methane Fermentation, Biotechnology and Bioengineering Symposium, 8:269-282 (1978). C528

[5] A. Husain, Mathematical Models of the Kinetics of Anaerobic Digestion, Biomass and Bioenergy, 14:561-571 (1998). doi:10.1016/S0961-9534(97)10047-2 C525

[6] D. J. Batstone, J. Keller, I. Angelidaki, S. V. Kalyuzzhni, S. G. Pavlostathis, A. Rozzi, W. T. M. Sanders, H. Siegrist and V. A Vavilin, Anaerobic Digestion Model No. 1 (ADM1), Water Science and Technology, 45:65-73 (2002). http://www. iwaponline.com/wst/04510/wst045100065.htm C525

[7] O. Levenspiel, Chemical Reaction Engineering, 3rd Ed., Wiley, New York (1999). C525

[8] J. F. Andrews, A Mathematical Model for the Continuous Culture of Microorganisms Utilizing Inhibitory Substrates, Biotechnology and Bioengineering, 10:707-723 (1968). doi:10.1002/bit.260100602 C526 
[9] K. J. Beers, Numerical Methods for Chemical Engineering: Applications in Matlab, Cambridge, New York, USA (2007). C526

\section{Author addresses}

1. A. A. Khan, School of Mathematical and Geospatial Sciences, RMIT University, Melbourne, Australia

2. A. J. Stacey, School of Mathematical and Geospatial Sciences, RMIT University, Melbourne, Australia

3. J. J. Shepherd, School of Mathematical and Geospatial Sciences, RMIT University, Melbourne, Australia mailto: jshep@rmit.edu.au 